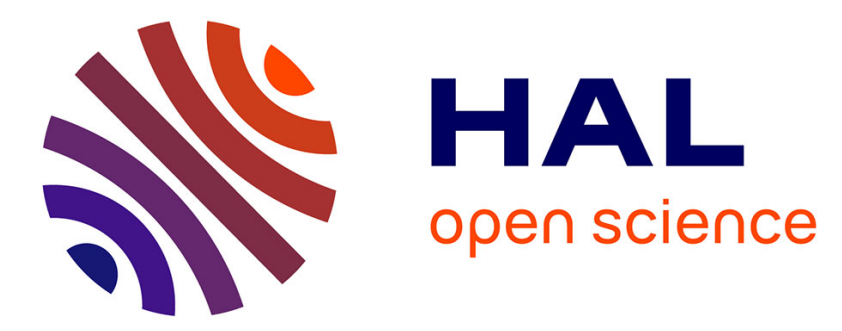

\title{
Fault-Tolerant Control Performance Comparison of Three- and Five-Phase PMSG for Marine Current Turbine Applications
}

Fatiha Mekri, Seifeddine Benelghali, Mohamed Benbouzid

\section{- To cite this version:}

Fatiha Mekri, Seifeddine Benelghali, Mohamed Benbouzid. Fault-Tolerant Control Performance Comparison of Three- and Five-Phase PMSG for Marine Current Turbine Applications. IEEE Transactions on Sustainable Energy , 2013, 4 (2), pp.425-433. 10.1109/TSTE.2012.2227126 . hal-00803242

\section{HAL Id: hal-00803242 \\ https://hal.science/hal-00803242}

Submitted on 21 Mar 2013

HAL is a multi-disciplinary open access archive for the deposit and dissemination of scientific research documents, whether they are published or not. The documents may come from teaching and research institutions in France or abroad, or from public or private research centers.
L'archive ouverte pluridisciplinaire HAL, est destinée au dépôt et à la diffusion de documents scientifiques de niveau recherche, publiés ou non, émanant des établissements d'enseignement et de recherche français ou étrangers, des laboratoires publics ou privés. 


\title{
Fault-Tolerant Control Performance Comparison of 3- and 5-Phase PMSG for Marine Current Turbine Applications
}

\author{
Fatiha Mekri, Seifeddine Ben Elghali, Member, IEEE and Mohamed Benbouzid, Senior Member, IEEE
}

\begin{abstract}
This paper deals with the use of permanent magnet multiphase generators in marine current turbines with the aim to highlight their fault-tolerance. In this context, the performances and the fault-tolerant capabilities of a 5-phase permanent magnet synchronous generator are evaluated within a marine current turbine and compared to a classical 3-phase generator. For both topologies, a robust nonlinear control strategy is adopted. The adopted control consists in an adaptive control approach that combines three strategies: an MPPT, an optimal fault-adaptive reference current generation, and high-order sliding modes.

Simulations are carried-out using a Matlab/Simulink®-based marine current turbine simulator to analyze the generator performances during open-circuit faults. Conclusions are then derived regarding multiphase generators key features for marine applications.
\end{abstract}

Index Terms-Marine current turbine, multiphase permanent magnet synchronous generator, open-circuit fault, fault-tolerant control, high-order sliding mode control.

\begin{tabular}{|c|c|c|}
\hline \multicolumn{3}{|r|}{ NOMENCLATURE } \\
\hline MCT & $=$ & Marine current turbine; \\
\hline PMSG & $=$ & Permanent magnet synchronous generator; \\
\hline MPPT & $=$ & Maximum Power Point Tracking; \\
\hline$v(i)$ & $=$ & PMSG voltage (current); \\
\hline$T$ & $=$ & PMSG torque; \\
\hline$\Omega$ & $=$ & PMSG speed; \\
\hline$k$ & $=$ & PMSG phase number; \\
\hline$z, p, s$ & $=$ & $\begin{array}{l}\text { zero sequence, primary and secondary } \\
\text { machines subscripts, respectively; }\end{array}$ \\
\hline$R_{s}$ & $=$ & PMSG stator resistance; \\
\hline$\phi_{s k}$ & $=$ & PMSG stator flux; \\
\hline$e_{k}$ & $=$ & PMSG emf; \\
\hline$L$ & $=$ & PMSG phase inductance; \\
\hline$M_{1}$ & $=$ & $\begin{array}{l}\text { PMSG mutual inductance between } \\
\text { two adjacent phases }( \pm 2 \pi / 5 \text { electrical shift })\end{array}$ \\
\hline$M_{2}$ & & $\begin{array}{l}\text { PMSG mutual inductance between } \\
\text { two phases shifted of } \pm 4 \pi / 5\end{array}$ \\
\hline$\Lambda$ & $=$ & Virtual machine inductance; \\
\hline$J$ & $=$ & Inertia; \\
\hline$f$ & $=$ & Viscous friction coefficient. \\
\hline
\end{tabular}

F. Mekri is with the University of Saida, 20000 Saida, Algeria, (e-mail: mekri_dz@yahoo.fr).

S. Ben Elghali is with the Aix-Marseille University, UMR CNRS 7296 LSIS, Avenue Escadrille Normandie-Niemen, 13397 Marseille Cedex 20, France (email: seifeddine.benelghali @ 1sis.org).

M.E.H. Benbouzid is with the University of Brest, EA 4325 LBMS, Rue de Kergoat, CS 93837, 29238 Brest Cedex 03, France (e-mail: Mohamed.Benbouzid@univ-brest.fr).

\section{INTRODUCTION}

Marine energy has become an issue of significant interest achieving a spectacular increase in the last years. It is currently the focus of much industrial and academic research around the world [1-3]. Indeed, the astronomic nature of this resource makes it predictable, to within $98 \%$ accuracy for decades, and independent of prevailing weather conditions. This predictability is critical to a successful integration of renewable energy in the electrical grid. Nevertheless, several marine energy projects over the world are facing difficulties delaying their complete achievement. These difficulties mainly concern installations high-cost and maintenance [4-5]. As marine current turbines are similar in many aspects to wind turbine technologies, their theoretical and experimental studies are essentially based on wind turbine experiences. Therefore, critical aspects, as availability and reliability, are emphasized by the analysis of the collected data from wind turbine farms. In this context, it has been shown that electrical and control system failures account for the highest percentage of failures [6-7]. Such failure high rate is not tolerable for MCTs due to site intervention and high maintenance costs. Furthermore, the marine environment harsh nature requires a long term planning beforehand to investigate human intervention periods [5]. In general, when one of these failures occurs, the MCT must be stopped for an unscheduled maintenance. As a result, normal system operation is interrupted, which will have serious consequences. Thus, the reliability of MCTs holds great interest for both engineers and researchers.

In this context, fault tolerance is gaining growing interest to increase the reliability and the continuous operation of electromechanical systems [8-9]. In the particular renewable power generation context, some researches have been conducted towards fault-tolerant three-phase generators [1013]. However, multiphase generators seem to be an interesting alternative to classical three-phase generators [14]. Indeed, multiphase generators offer additional degrees of freedom that can be used for fault-tolerant operation. In fact, under fault conditions, their remaining healthy phases can be used to compensate the faults and continue the MCT operation [15-18].

In order to highlight the superiority of multiphase generators (more than 3 phases) in terms of robustness, faulttolerance, and efficiency for marine current applications, a comparative study with a classical 3-phase generator is presented in this paper. This comparison is carried-out under normal and faulty operation conditions [15-16]. The generator performances are evaluated using an MCT simulator environment which has been previously developed [3]. 
Moreover, an optimal control strategy for healthy and faulty operation mode is proposed. It consists in an adaptive control approach that combines three strategies: an MPPT, an optimal fault-adaptive reference current generation, and high-order sliding modes [19]. In this study, the generator performances are analyzed under an open-circuit mode for the same hydrodynamic input torque and the same extracted power.

\section{MCT MODELING BRIEFLY}

\section{A. MCT Simulator [3]}

The Matlab/Simulink®-based MCT simulator has adopted a multiphysics approach to model the whole system, including the resource, the rotor, the gearbox, and the generator (Fig. 1). This simulator can evaluate marine current turbine performances and dynamic loads over different operating conditions. Moreover, it should be used to quantify the potential for generating electricity from various sites and various technology choices and therefore evaluate their costeffectiveness. Currently, the MCT simulator incorporates several types of turbines models. The various components of the simulator (marine current resource, turbine hydrodynamics, generator, and converter models) have been tested and experimentally validated in terms of models and speed control performances. Due to the simulator modularity, the 5-phase PMSG has been easily incorporated and investigated.

\section{B. 5-Phase PMSG Model}

The 3-phase PMSG mode is already described in [3]. A 5phase PMSG electric model in a natural base is given for the $k^{\text {th }}$ phase by

$v_{k}=R_{s} i_{k}+\frac{d \phi_{s k}}{d t}+e_{k}$

Assuming that the $k$ phases are regularly shifted and there is no saturation and no saliency effects; the following can be obtained [20-22].

$$
\left\{\begin{array}{l}
\overrightarrow{\boldsymbol{\phi}}_{s}=\lambda(\overrightarrow{\boldsymbol{i}}) \\
{\left[L_{s}^{n}\right]=\operatorname{mat}\left(\lambda, B^{n}\right)=\left[\begin{array}{ccccc}
L & M_{1} & M_{2} & M_{2} & M_{1} \\
M_{1} & L & M_{1} & M_{2} & M_{2} \\
M_{2} & M_{1} & L_{1} & M_{1} & M_{2} \\
M_{2} & M_{2} & M_{1} & L & M_{1} \\
M_{1} & M_{2} & M_{2} & M_{1} & L
\end{array}\right]}
\end{array}\right.
$$

Phase magnetic couplings make multiphase generators control more complex [14]. Model (1) is interesting in terms of simulation. However, dynamic regimes analytical expression is difficult to formulate. To simplify dynamic control, it is possible to work in a base in which the phases are magnetically decoupled. Using a generalization of the Concordia transform, (1) can be rewritten in this new base [22-23]. Hence, (1) can be decomposed in three independent 2D and 1D subsystems, which can be assimilated to two 2-phase and one 1-phase machines. These three machines are respectively called zero sequence machine ( $z-1 \mathrm{D}$ system), primary (PrM), and secondary $(\mathrm{SdM})$ machines that are associated to $\left(\alpha_{p}, \beta_{p}\right)$ and $\left(\alpha_{s}, \beta_{s}\right)$. A new model is then deduced in the $[z, \alpha, \beta]$ plane.

$$
\begin{aligned}
& \left\{\overrightarrow{\boldsymbol{v}}_{z}=R_{s} \overrightarrow{\boldsymbol{i}}_{z}+\Lambda_{z} \frac{d \overrightarrow{\boldsymbol{i}}_{z}}{d t}+\overrightarrow{\boldsymbol{e}}_{z}\right. \\
& \left\{\overrightarrow{\boldsymbol{v}}_{\alpha \beta-p}=R_{s} \overrightarrow{\boldsymbol{i}}_{\alpha \beta-p}+\Lambda_{p} \frac{d \overrightarrow{\boldsymbol{i}}_{\alpha \beta-p}}{d t}+\overrightarrow{\boldsymbol{e}}_{\alpha \beta-p}\right. \\
& \overrightarrow{\boldsymbol{v}}_{\alpha \beta-s}=R_{s} \overrightarrow{\boldsymbol{i}}_{\alpha \beta-s}+\Lambda_{s} \frac{d \overrightarrow{\boldsymbol{i}}_{\alpha \beta-s}}{d t}+\overrightarrow{\boldsymbol{e}}_{\alpha \beta-s} \\
& \text { where }\left\{\begin{array}{l}
\Lambda_{p}=L-2\left[M_{1} \cos \left(\frac{2 \pi}{5}\right)+M_{2} \cos \left(\frac{\pi}{5}\right)\right] \\
\Lambda_{s}=L-2\left[M_{1} \cos \left(\frac{\pi}{5}\right)+M_{2} \cos \left(\frac{3 \pi}{5}\right)\right]
\end{array}\right.
\end{aligned}
$$

Each of those subsystems is associated with a harmonic family.

$$
\left\{\begin{array}{l}
\overrightarrow{\boldsymbol{e}}_{z}=\sqrt{5} \sum_{k} E^{k} \sin (h p \theta) \overrightarrow{\boldsymbol{x}}_{z}, \quad k=5,15, \ldots \\
\overrightarrow{\boldsymbol{e}}_{\alpha \beta-p}=\sqrt{\frac{5}{2} \sum_{k} E^{k}\left[\sin (h p \theta) \overrightarrow{\boldsymbol{x}}_{p \alpha}-\cos (h p \theta) \overrightarrow{\boldsymbol{x}}_{p \beta}\right], \quad k=1,9, \ldots} \\
\overrightarrow{\boldsymbol{e}}_{\alpha \beta-s}=\sqrt{\frac{5}{2}} \sum_{k} E^{k}\left[\sin (h p \theta) \overrightarrow{\boldsymbol{x}}_{s \alpha}+\cos (h p \theta) \overrightarrow{\boldsymbol{x}}_{s \beta}\right], \quad k=3,7, \ldots
\end{array}\right.
$$

As the generator is wye-coupled, the current zero sequence component is null $\left(i_{\mathrm{z}}=0\right)$. With this harmonic distribution, each of the above two generators is characterized by a particular harmonic family: PrM harmonic family contains the $1^{\text {st }}, 9^{\text {th }}$ and $11^{\text {th }}$ harmonics and SdM family contains the $3^{\text {rd }}, 7^{\text {th }}$ and $13^{\text {th }}$ ones [20-21].

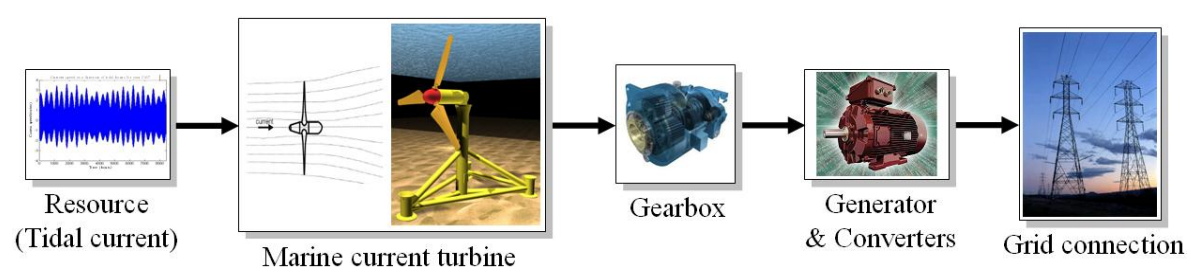

Fig. 1. Marine current turbine global scheme. 
It can therefore be considered that the primary machine has $p$ pole pairs and the secondary one has $3 p$ pole pairs. As shown in (3), the system behaves as if there were two 2-phase machines mechanically coupled but magnetically decoupled. It is therefore possible to control the primary (main) and secondary machine currents independently. These two machines significantly contribute to the electromagnetic torque. This torque is given by

$$
\left\{\begin{array}{l}
T_{e m}=\frac{\overrightarrow{\boldsymbol{e}}}{\Omega}=\frac{\overrightarrow{\boldsymbol{e}}_{p} \overrightarrow{\boldsymbol{i}}_{p}+\overrightarrow{\boldsymbol{e}}_{s} \overrightarrow{\boldsymbol{i}}_{s}}{\Omega} \\
T_{e m}=T_{p}+T_{s}
\end{array}\right.
$$

In order to produce a significant torque, the first harmonic of the above two 2-phase machines is controlled. The reference current in each phase is a compound of the primary machine fundamental currents and the secondary one third harmonic currents. The control of a 5-phase PMSG can therefore be simplified by the use of two appropriate Park transforms associated to the 2-phase machines (3). These transforms lead to define two $d-q$ rotating frames (6). The first frame is associated to the first harmonic and rotates at $\omega$, and the second one, with the third harmonic and rotates at $-3 \omega$. An homopolar frame is also obtained. It corresponds to the fifth order harmonics. These transforms are a generalization of the Park transform to multiphase systems [21]. In this case, the reference currents are constant in normal operation steady-state in the two $d-q$ rotating frames [23]. Therefore, direct control of the current $q$-component of the two 2-phase machines allows independently controlling the two machines and the global system electromagnetic torques.

In this context, the stator voltages can be expressed as

$$
\left\{\begin{array}{l}
V_{d p}=R_{s} I_{d p}-\omega \Lambda_{p} I_{q p}+E_{d p}+\Lambda_{p} \frac{d I_{d p}}{d t} \\
V_{q p}=R_{s} I_{q p}+\omega \Lambda_{p} I_{d p}+E_{q p}+\Lambda_{p} \frac{d I_{q p}}{d t} \\
V_{d s}=R_{s} I_{d s}-3 \omega \Lambda_{s} I_{q s}+E_{d s}+\Lambda_{s} \frac{d I_{d s}}{d t} \\
V_{q s}=R_{s} I_{q s}+3 \omega \Lambda_{s} I_{d s}+E_{q s}+\Lambda_{s} \frac{d I_{q s}}{d t}
\end{array}\right.
$$

In this two $d-q$ frames, the steady-state currents and voltages remain constant. This will lead to an easier control.

Adding the following dynamic equation

$T_{e m}=J \frac{d \Omega}{d t}+f \Omega=T_{e m_{-} p}+T_{e m_{-} s}$

will allow the 5-phase PMSG electromechanical behavior modeling with (5) and (6).

\section{PMSG-BASED MCT CONTROL}

\section{A. Control Principle}

An MPPT-based variable speed strategy has been adopted for the MCT [19]. Moreover, high-order (second-order) sliding mode has been adopted for the control of the PMSG-based marine current turbine. This robust control approach has been chosen mainly due to the tidal resource characteristics such as turbulence and swell effects and the inevitable uncertainties inherent in PMSG-based MCTs [3]. Indeed, although many modern techniques can be used for this purpose, sliding mode control has proved to be especially appropriate for nonlinear systems, presenting robust features with respect to system parameter uncertainties and external disturbances [24-25]. Finally, to ensure the 5-phase PMSG fault-tolerant operation with minimum copper losses (efficiency optimization), an adaptive control strategy is proposed.

Figure 2 illustrates the proposed PMSG-based MCT control scheme.

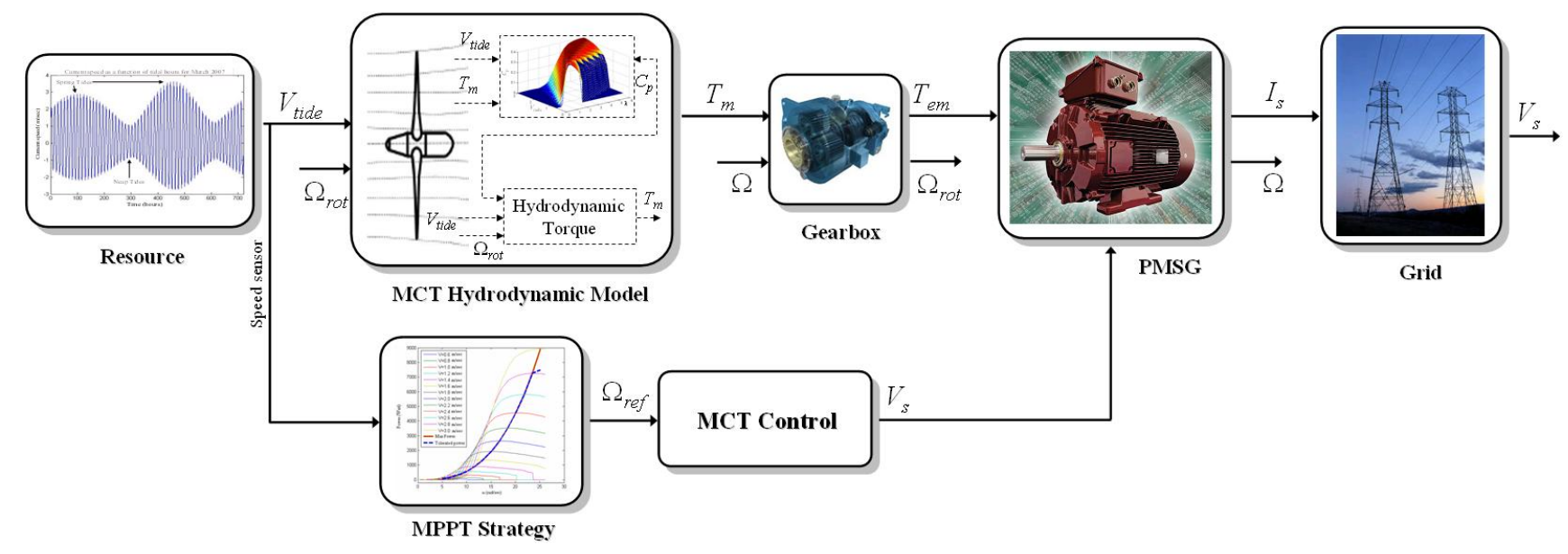

Fig. 2. The proposed PMSG-based MCT control scheme. 


\section{B. Reference Current}

In normal operation, minimizing copper losses for a constant given torque $T_{\max }$ leads to express the optimal reference current of each phase as [20-21], [26].

$\overrightarrow{\boldsymbol{i}}_{\text {ref }}=A \frac{\overrightarrow{\boldsymbol{e}}}{\Omega} \quad$ with $A=\frac{T_{\max }}{\left\|\frac{\overrightarrow{\boldsymbol{e}}}{\Omega}\right\|^{2}}$

Let us consider a faulty case where one phase of a PMSG is not supplied ( $i^{\text {th }}$ phase for example) and where the machine has a sinusoidal emf. Using the above described classical control will lead to the following electromagnetic torque.

$$
T_{e m-F}(\omega t)=\frac{T_{e m-H}}{n}\left[(n-1)+\cos \left(2 \omega t-2(i-1) \frac{2 \pi}{n}\right)\right]
$$

Where $T_{e m-H}$ is the healthy machine developed torque and $n$ is the phase number.

It is obvious that faulty operations lead to torque ripple high values (second term of (9)). These ripples are due to interactions between the currents nonsymmetrical system with the emf symmetrical one.

Therefore, to avoid these ripples an adaptive control method is proposed to determine specific reference currents. To ensure the 5-phase PMSG operation continuity (faulttolerance) with minimum copper losses (efficiency) when an open-phase fault occurs, an adaptive control strategy has been previously proposed in [21]. In this method the faulty phases are firstly detected. Then a new system is considered. This new system only comprises the healthy phases. For example, in case of one or two faulty phases the new emf vector for each healthy phase (here the first phase) is given by

$e_{1}=e_{1}-\frac{1}{q} \sum_{k=1}^{q} h_{k} e_{k}$

where $q^{\prime}$ is the active phase number and $h_{k}=1$ for an active phase and $h_{k}=0$ for a faulty one.

Therefore (9) is rewritten as follows.

$$
\overrightarrow{\boldsymbol{i}}_{\text {ref }}=A^{\cdot} \frac{\overrightarrow{\boldsymbol{e}}^{\prime}}{\Omega} \quad \text { with } A=\frac{T_{\max }}{\left\|\frac{\overrightarrow{\boldsymbol{e}}^{\prime}}{\Omega}\right\|^{2}}
$$

This strategy remains valid in normal and faulty operations to achieve a constant and filtered torque at minimum copper losses. Figure 3 illustrates the general structure of this online control strategy.

\section{Second-Order Sliding Mode Control}

The PMSG-based MCT proposed control strategy has been previously applied and tested in [3]. It is now extended to the 5-phase PMSG. It is based on a step-by-step procedure:

1) First, the speed reference $\omega_{\text {ref }}$ is generated by a Maximum Power Point Tracking (MPPT) strategy.

2) Then, an optimal electromagnetic torque, which ensures the rotor speed convergence to $\omega_{\text {ref }}$ is computed using the following equation.

$$
T_{e m_{-} r e f}=T_{m}+f \omega-\alpha\left(\omega-\omega_{r e f}\right)+J \dot{\omega}_{r e f}
$$

Where $\alpha$ is a positive constant. Afterwards, reference currents are derived to ensure the PMSG torque convergence to the optimal one and to minimize the error between the current and its reference Let us define the following sliding surfaces for the first $d-q$ frames (A similar approach is done for the second $d-q$ frame).

$\left\{\begin{array}{l}S_{1 p}=I_{d p}-I_{d p_{-} r e f} \\ S_{2 p}=I_{q p}-I_{q p_{-} r e f}\end{array}\right.$

It follows that $\left\{\begin{array}{l}\dot{S}_{1 p}=\dot{I}_{d p}-\dot{I}_{d p_{-} r e f} \\ \ddot{S}_{1 p}=\varphi_{1}(t, x)+\gamma_{1}(t, x) \dot{V}_{d p}\end{array}\right.$

and $\left\{\begin{array}{l}\dot{S}_{2 p}=\dot{I}_{q p}-\dot{I}_{q p_{-} \text {ref }} \\ \ddot{S}_{2 p}=\varphi_{2 p}(t, x)+\gamma_{2}(t, x) \dot{V}_{q p}\end{array}\right.$

Where $\varphi_{1}(t, x), \quad \varphi_{2}(t, x), \quad \gamma_{1}(t, x)$, and $\gamma_{2}(t, x)$ are uncertain bounded functions that satisfy

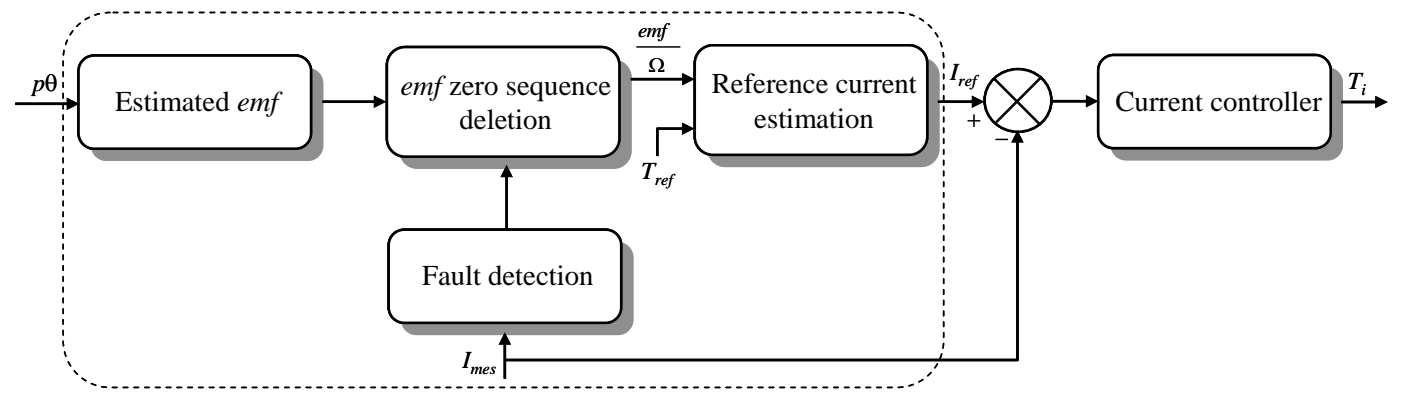

Fig. 3. Scheme of the adaptive strategy to determine reference currents. 
$\begin{cases}\varphi_{1}>0, & \left|\varphi_{1}\right|>\Phi_{1}, \quad 0<\Gamma_{m 1}<\gamma_{1}<\Gamma_{M 1} \\ \varphi_{2}>0, & \left|\varphi_{2}\right|>\Phi_{2}, \quad 0<\Gamma_{m 2}<\gamma_{2}<\Gamma_{M 2}\end{cases}$

The proposed second-order sliding mode control has been designed using the super twisting algorithm. The controller contains two parts:

$\left\{\begin{array}{l}V_{d p}=u_{1}+u_{2} \\ V_{q p}=w_{1}+w_{2}\end{array}\right.$

where $\left\{\begin{array}{l}\dot{u}_{1}=-\alpha_{1} \operatorname{sign}\left(S_{1}\right) \\ u_{2}=-\beta_{1}\left|S_{1}\right|^{\rho} \operatorname{sign}\left(S_{1}\right)\end{array}\right.$ and $\left\{\begin{array}{l}\dot{w}_{1}=-\alpha_{2} \operatorname{sign}\left(S_{2}\right) \\ w_{2}=-\beta_{2}\left|S_{2}\right|^{\rho} \operatorname{sign}\left(S_{2}\right)\end{array}\right.$

To ensure the sliding manifolds convergence to zero in finite time, the gains can be chosen as follows [27].

$$
\left\{\begin{array}{l}
\alpha_{i}>\frac{\Phi_{i}}{\Gamma_{m i}} \\
\beta_{i}{ }^{2} \geq \frac{4 \Phi_{i}}{\Gamma_{m i}{ }^{2}} \frac{\Gamma_{M i}\left(\alpha_{i}+\Phi_{i}\right)}{\Gamma_{m i}\left(\alpha_{i}-\Phi_{i}\right)} ; \quad i=1,2 \\
0<0 \leq 0.5
\end{array}\right.
$$

\section{5-PHASE PMSG-BASED MCT PERFORMANCE EVALUATION}

Simulations are carried-out using the MCT simulator with a typical tidal resource cycle (Fig. 4). Simulation scale has been reduced from two tidal cycles (approximately 24 hours) to 100 seconds.

In this context, the 5-phase PMSG control is based on the control of the two virtual generators in the two $d$ - $q$ frames. It consists in the combination of three strategies: an MPPT, an optimal fault-adaptive reference current generation, and second-order sliding modes.

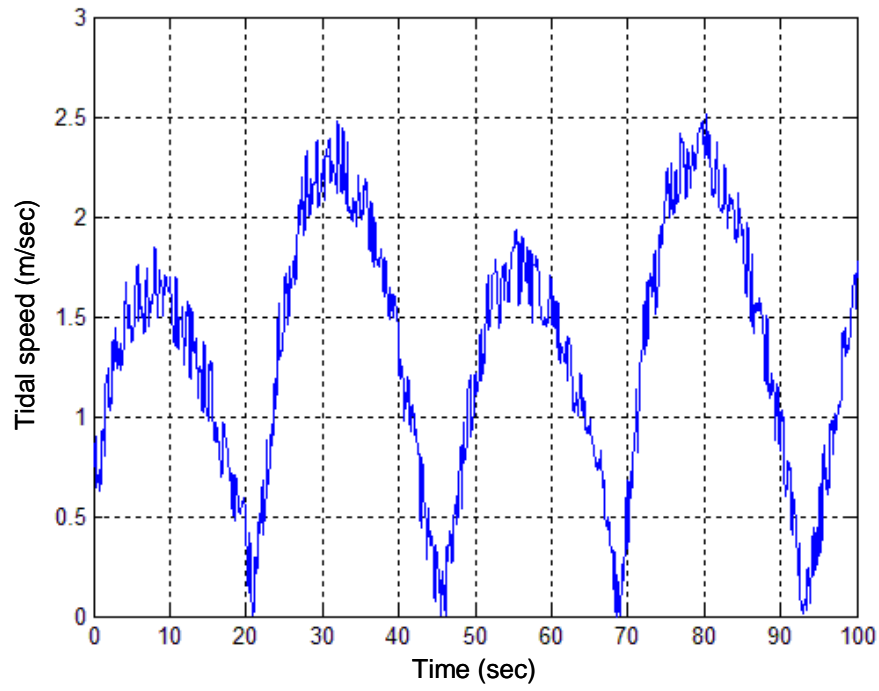

Fig. 4. Typical turbulent resource speed.

\section{A. Normal Condition Operation}

The 5-phase PMSG-based MCT control performances in healthy conditions are shown in Figs. 5 to 8 respectively illustrating the rotor speed, the generated power, the mechanical torque and the currents. The obtained results show good tracking performances of the 5-phase PMSG rotor speed and currents. They clearly illustrate the effectiveness of the proposed control strategy in healthy conditions.

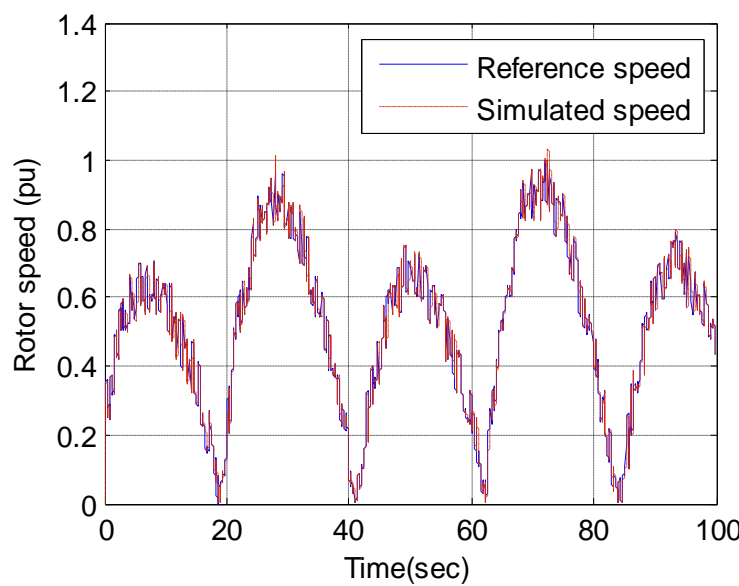

Fig. 5. 5-Phase PMSG speed and its reference in healthy mode.

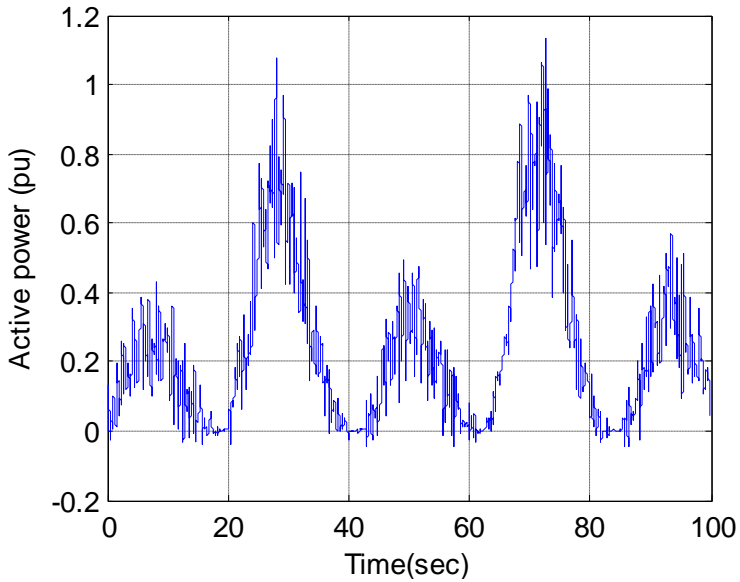

Fig. 6. MCT generated active power in healthy mode.

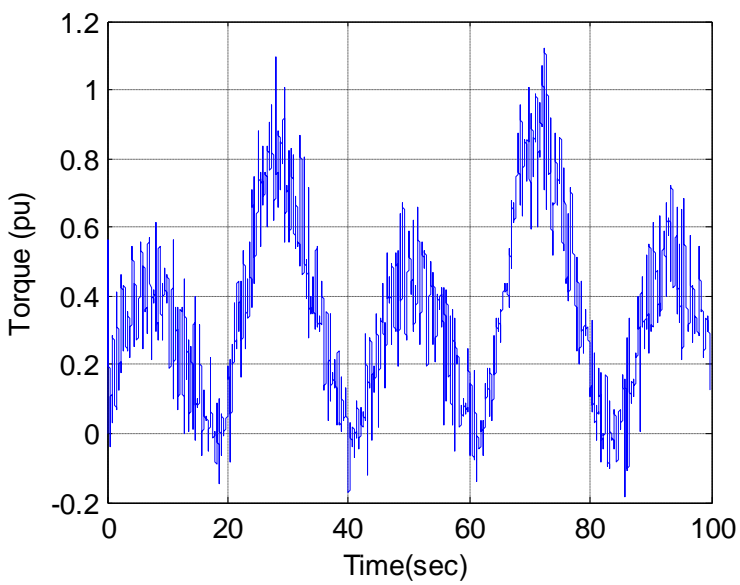

Fig. 7. MCT mechanical torque in healthy mode. 


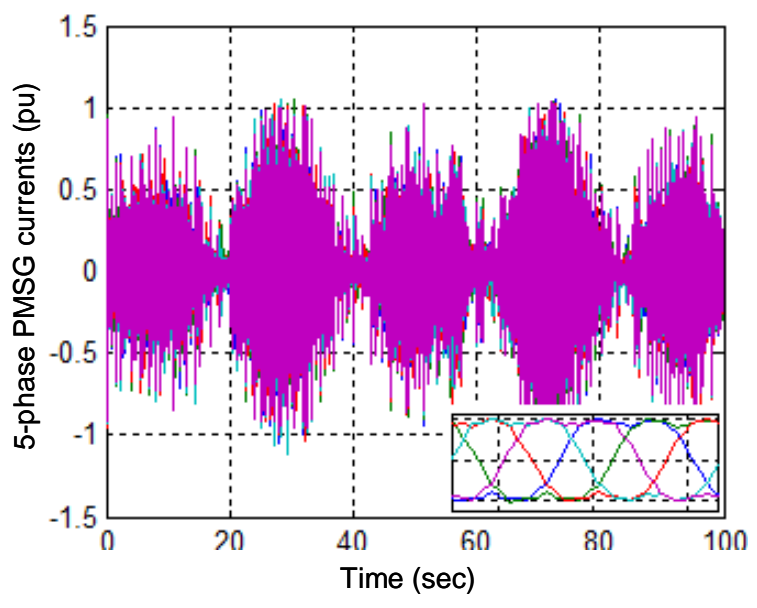

Fig. 8. 5-Phase PMSG current in healthy mode.

\section{B. Operation under Open-Circuit Fault Conditions}

The fault-tolerant capabilities are now evaluated under open-circuit fault conditions. Simulation results are given in Figs. 9 to 12 respectively illustrating the rotor speed, the generated power, the mechanical torque and the currents when the $1^{\text {st }}$ phase is opened.

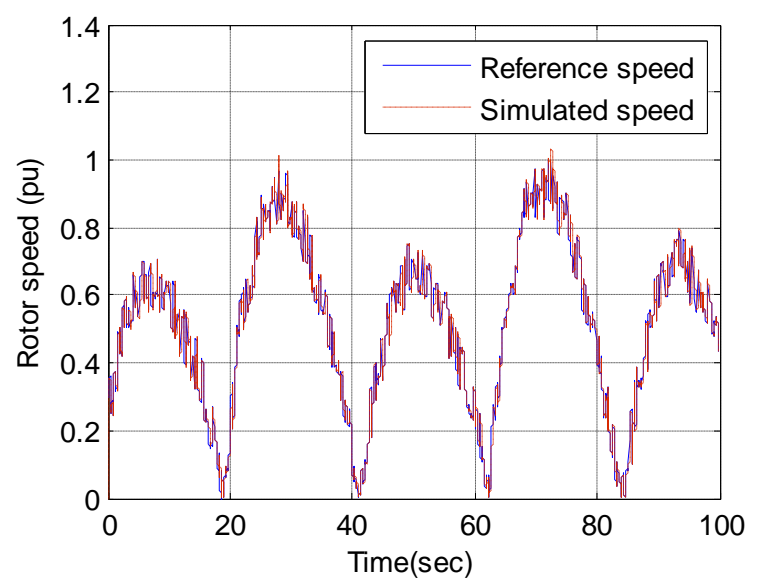

Fig. 9. 5-Phase PMSG speed and its reference in faulty mode.

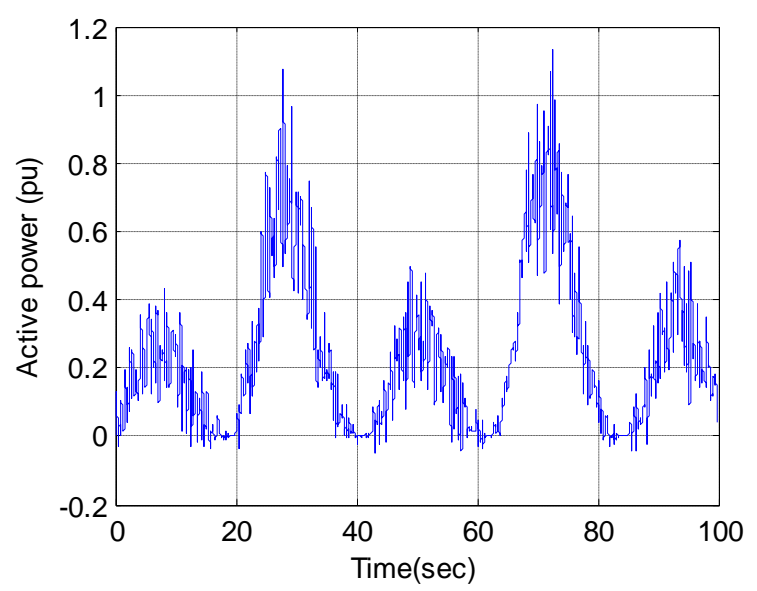

Fig. 10. MCT generated active power in faulty mode.

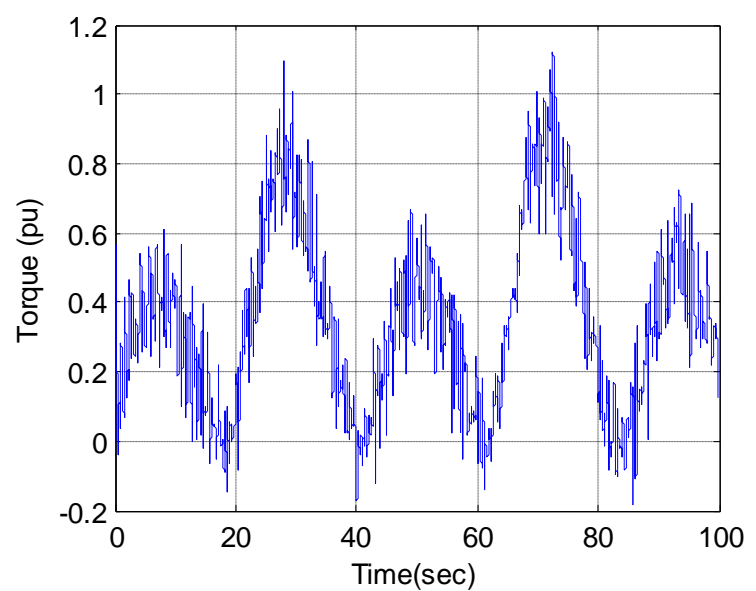

Fig. 11. MCT mechanical torque in faulty mode.

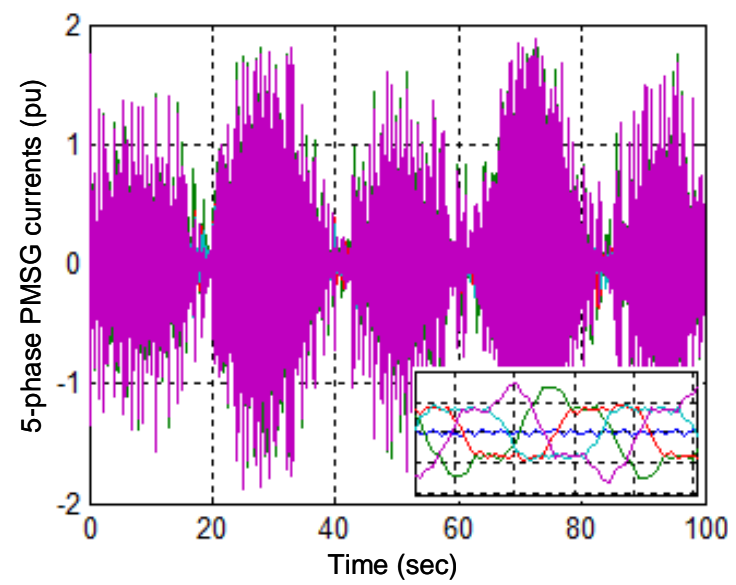

Fig.12. 5-Phase PMSG current in faulty mode.

In this case good tracking performances are achieved in terms of speed and currents which prove that the proposed second-order sliding mode control approach is efficient for fault-tolerant operations. Indeed in this faulty mode, the 5phase PMSG-based MCT generated power and the torque remains smooth as in the healthy mode (Figs. 10 and 11). Moreover, no mechanical extra stresses are induced in the MCT (Fig. 11). However, it has been noticed an increase of the current of the 5-phase PMSG from 1 to $1.5 \mathrm{pu}$ compared to the healthy mode (Fig. 12). This was a predictable result. Indeed, the generator performances are analyzed for the same hydrodynamic input torque and the same extracted power.

\section{3- AND 5-PHASE PMSG-B ASED MCT COMPARATIVE STUDY USING THE MCT SIMULATOR}

The 3- and 5-phase PMSGs comparative study has have been carried-out using the above cited MCT simulator. In this case, simulations are based on 2-kW PMSG-based MCT with a constant tidal resource for comparison simplification in contrary to section IV. Moreover, generator comparisons were made for the same torque and the same generated power. Both simulated generators are connected with a diode rectifier, a smoothing capacitor, and a resistive load. 
It should be mentioned that the 5-phase PMSG control is the same as the one presented in the previous section.

\section{A. Healthy Condition Operation}

The 3- and 5-phase PMSG-based MCTs control performances in healthy conditions are shown in Figs. 13 to 18 , respectively illustrating the rotor speed, the generated power, the mechanical torque, the generator currents, and the DC bus voltage. These simulation results lead to the following main conclusions:

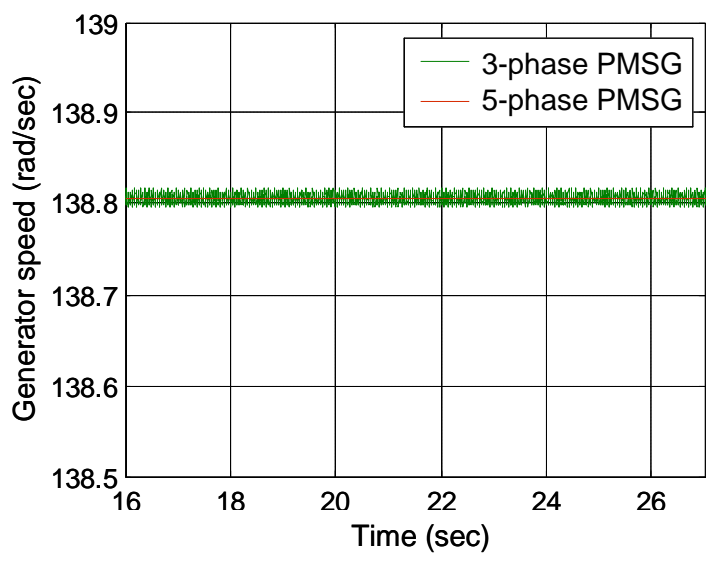

Fig. 13. MCT generator speed in healthy mode.

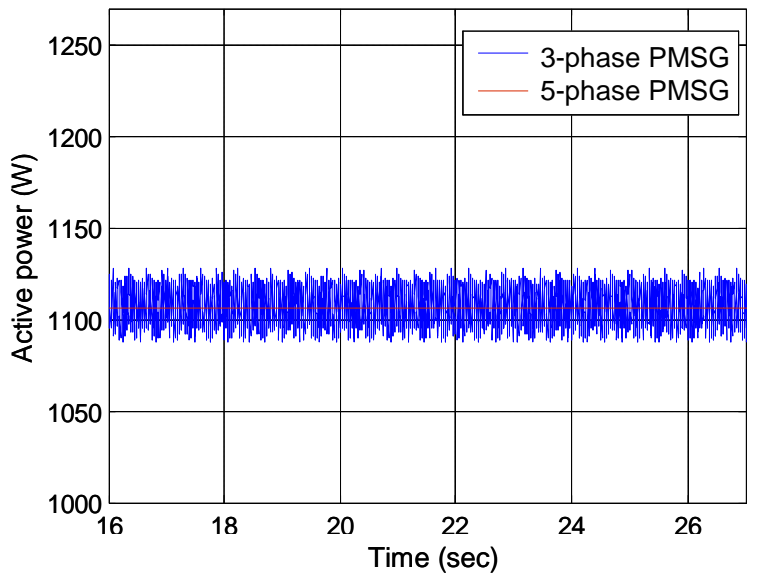

Fig. 14. MCT generated active power in healthy mode.

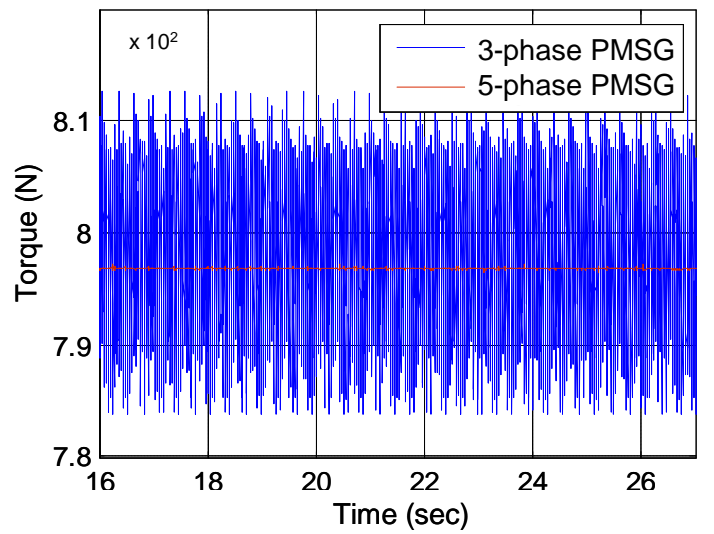

Fig. 15. MCT mechanical torque in healthy mode.
- The 5-phase PMSG-based MCT generated power is very smooth (Fig. 14).

- The peak-to-peak torque ripples are significantly reduced with a 5-phase PMSG (Fig. 15).

- There is no noticeable difference between DC bus voltages with a 3-phase and 5-phase PMSG-based MCT. This is mainly due to the adopted adaptive control strategy, in contrary to a classical approach [28].

It is therefore obvious that a multiphase generator is more appropriate for MCTs than a classical 3-phase generator, even in normal operation.

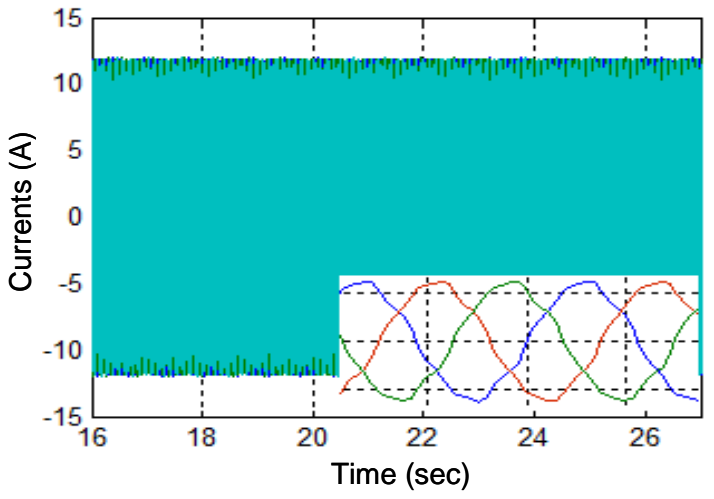

Fig. 16. 3-phase PMSG currents in healthy mode.

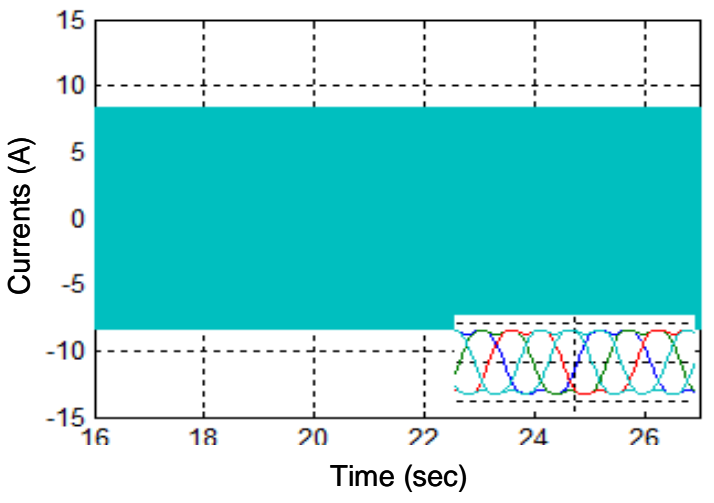

Fig. 17. 5-phase PMGS currents in healthy mode.

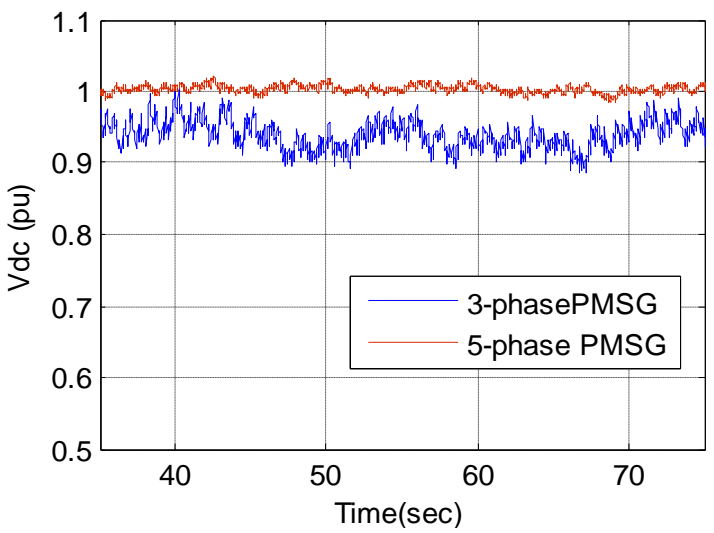

Fig. 18. MCT DC bus voltage in healthy mode. 


\section{B. Operation under Open-Circuit Fault Conditions}

The two generators performances are now evaluated under an open-circuit in the first phase. In this case, a reference current is now online determined under faulty conditions to achieve a constant and smooth torque, equals to the one under healthy conditions, and leading to minimum copper losses.

Simulation results are shown in Figs. 19 to 23, respectively illustrating the generated power, the mechanical torque, the generator currents, and the DC bus voltage. These simulation results lead to the following main conclusions:

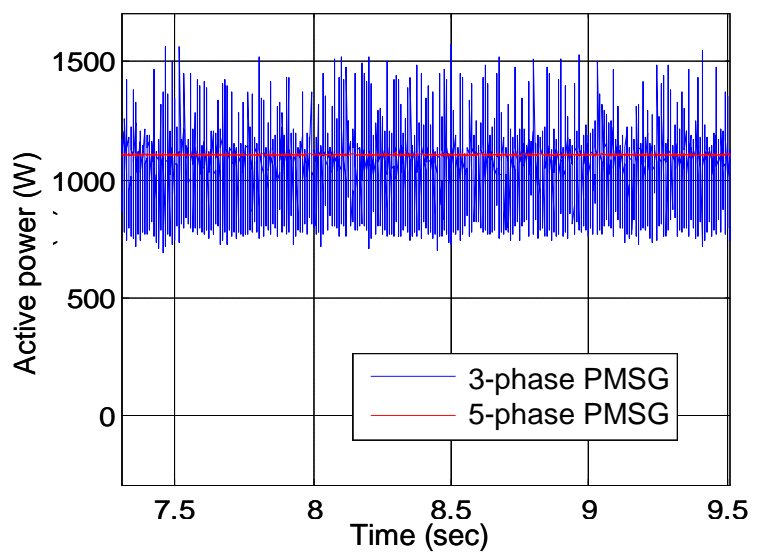

Fig. 19. MCT generated active power in faulty mode.

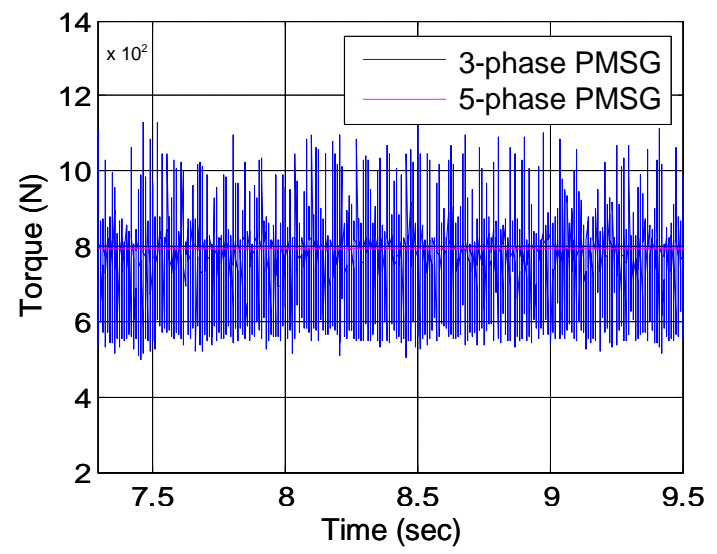

Fig. 20. MCT torque in faulty mode.

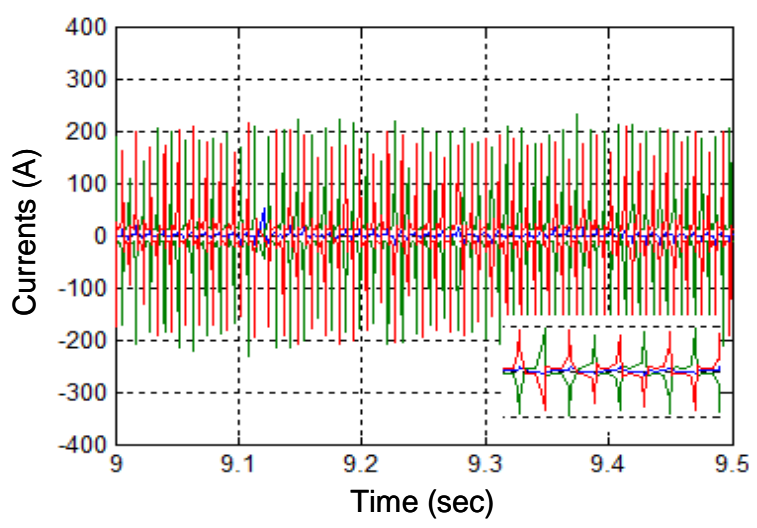

Fig. 21. 3-phase PMGS currents in faulty mode.
- The 5-phase PMSG-based MCT generated power is still quiet smooth even in faulty conditions (Fig. 19).

- The torque ripples are significantly reduced with a 5phase PMSG thanks to the proposed control strategy (Fig. 20) [26]. Indeed, the torque remains quiet smooth. Therefore, no extra stresses are induced in the MCT drive train.

- The 3-phase PMSG currents increase is quiet huge compared to the 5-phase one. In this case, the failed generator is now equivalent to a single-phase one.

- With an opened phase, a 5-phase PMSG is still capable of providing about $100 \%$ DC bus voltage. Indeed, the open-circuit has no impact on the DC bus voltage. This is not the case for the 3-phase PMSG for which the DC bus voltage increases about $20 \%$ over the rated value. With the same failure and a classical control strategy, a 3-phase PMSG is capable of providing only $85 \%$ of the rated DC bus voltage, and a 5-phase PMSG around 93\% with voltage ripples [26].

The analysis of the above presented performances under faulty conditions confirms the fact that a multiphase generator is clearly a candidate of choice for a marine current turbine.

\section{CONCLUSION}

This paper dealt with the use of permanent magnet multiphase marine current turbine generators.

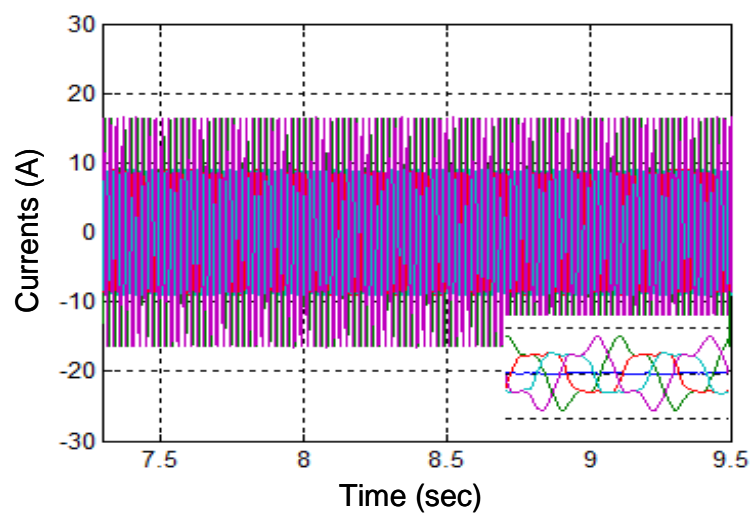

Fig. 22. 5-phase PMGS currents in faulty mode.

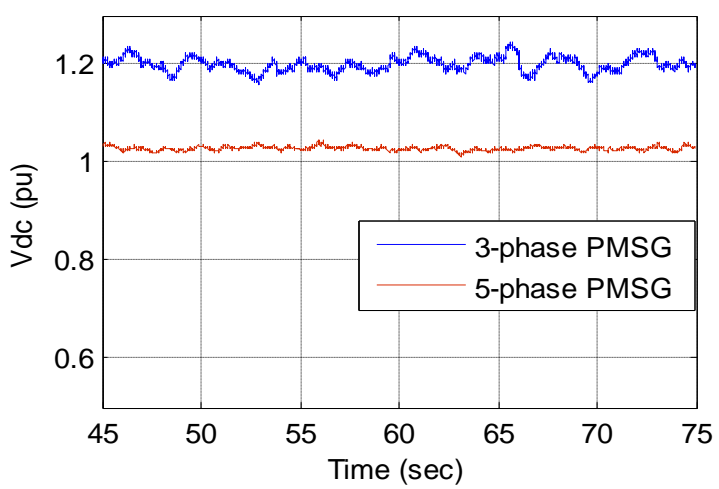

Fig. 23. MCT DC bus voltage in faulty mode. 
In this context, the performances and the fault-tolerant capabilities of a 5-phase permanent magnet synchronous generator have been evaluated within a marine current turbine and compared to a classical 3-phase generator. For both topologies, a robust nonlinear control strategy has been adopted. The control consisted in an adaptive control approach that combines three strategies: an MPPT, an optimal fault-adaptive reference current generation, and second-order sliding modes using a super twisting algorithm. In faulty conditions, a reference current was online determined to achieve a constant and smooth torque, equals to the one under normal conditions, and leading to minimum copper losses.

Simulations have been carried-out using a Matlab/Simulink®-based marine current turbine simulator. The obtained results clearly show that, even in normal operation, a multiphase generator is clearly a candidate of choice for marine current turbine applications, in comparison to a classical 3-phase generator. In particular, it has been demonstrated that a 5-phase topology is effective for achieving electrical fault-tolerant operation in an MCT. This will obviously increase the system reliability.

\section{REFERENCES}

[1] M.S. Güney and K. Kaygusuz, "Hydrokinetic energy conversion systems: A technology status review," Renewable and Sustainable Energy Reviews, vol. 14, n9, pp. 2996-3004, December 2010.

[2] M.J. Khan and G. Bhuyan, M.T. Iqbal and J.E. Quaicoe, "Hydrokinetic energy conversion systems and assessment of horizontal and vertical axis turbines for river and tidal applications: A technology status review," Applied Energy, vol. 86, n¹0, pp. 1823-1835, October 2009.

[3] S. Benelghali, M.E.H. Benbouzid, J.F Charpentier, T. Ahmed-Ali and I. Munteanu, "Experimental validation of a marine current turbine simulator: Application to a PMSG-based system second-order sliding mode control," IEEE Trans. Industrial Electronics, vol. 58, n¹, pp. 118-126, January 2011.

[4] E. Omerdic, D. Toal, S. Nolan, H. Ahmad and G. Duffy, "Design \& development of assistive tools for future applications in the field of renewable ocean energy," in Proceedings of the 2011 IEEE OCEANS, Santander (Spain) pp. 1-6, June 2011.

[5] Y. Li and H.K. Florig, "Modeling the operation and maintenance costs of a large scale tidal current turbine farm," in Proceedings of the IEEE OCEANS'06, Boston (USA), September 2006.

[6] S. Faulstich, B. Hahn and P. J. Tavner, "Wind turbine downtime and its important for offshore deployment," Wind Energy, vol. 14, n³, pp. 327337, April 2011.

[7] Y. Amirat, M.E.H. Benbouzid, E. Al-Ahmar, B. Bensaker and S. Turri, "A brief status on condition monitoring and fault diagnosis in wind energy conversion systems," Renewable \& Sustainable Energy Reviews, vol. 3, $\mathrm{n}^{\circ}$ 9, pp. 2629-2636, December 2009.

[8] M. Muenchhof, M. Beck and R. Isermann, "Fault-tolerant actuators and drives-Structures, fault detection principles and applications," Annual Reviews in Control, vol.33, n², pp. 136-148, December 2009.

[9] D.U. Campos-Delgado, D.R. Espinoza-Trejo and E. Palacios, "Faulttolerant control in variable speed drives: a survey," IET Electric Power Applications, vol.2, n², pp. 121-134, March 2008.

[10] M.A. Parker, N. Chong and L Ran, "Fault-tolerant control for a modular generator-converter scheme for direct-drive wind turbines," IEEE Trans. Industrial Electronics, vol. 58, n ${ }^{\circ}$, pp. 305-315, January 2011.

[11] K. Rothenhagen and F.W. Fuchs, "Doubly fed induction generator modelbased sensor fault detection and control loop reconfiguration," IEEE Trans. Industrial Electronics, vol. 56, n 10, pp. 4229-4238, October 2009.

[12] K. Rothenhagen and F.W. Fuchs, "Current sensor fault detection, isolation, and reconfiguration for doubly fed induction generators," IEEE Trans. Industrial Electronics, vol. 56, n 10, pp. 4239-4245, October 2009.
[13] S. Karimi, A. Gaillard, P. Poure and S. Saadate, "Current sensor faulttolerant control for WECS with DFIG," IEEE Trans. Industrial Electronics, vol. 56, $\mathrm{n}^{\circ} 11$, pp. 4660-4670, November 2009.

[14] E. Levi R. Bojoi, F. Profumo, H.A. Toliyat and S.Williamson, "Multiphase induction motor drives - a technology status review," IET Electric Power Applications, vol. 1, n4, pp. 489-516, July 2007.

[15] F. Mekri, S. Benelghali, M.E.H. Benbouzid and J.F. Charpentier, "A Fault-tolerant multiphase permanent magnet generator for marine current turbine applications," in Proceedings of the 2011 IEEE ISIE, Gdansk (Poland), pp. 2079-2084, June 2011.

[16] S. Benelghali, F. Mekri, M.E.H. Benbouzid and J.F. Charpentier, "Performance comparison of three- and five-phase permanent magnet generators for marine current turbine applications under open-circuit faults," in Proceedings of the 2011 IEEE POWERENG, Malaga (Spain), pp. 1-6, May 2011.

[17] S. Dwari and L. Parsa, "Fault-tolerant control of five-phase permanentmagnet motors with trapezoidal back EMF," IEEE Trans. Industrial Electronics, vol. 58, n², pp. 476-485, February 2011.

[18] A.A. Abd Hafez, R. Todd, A.J. Forsyth and A.M. Cross, "Direct current ripple compensation for multi-phase fault-tolerant machines," IET Electric Power Applications, vol. 5, n 1, pp. 28-36, January 2011.

[19] S. Benelghali, M.E.H. Benbouzid, T. Ahmed-Ali and J.F. Charpentier, "High-order sliding mode control of a marine current turbine driven doubly-fed induction generator," IEEE Journal of Oceanic Engineering, vol. $35, \mathrm{n}^{\circ} 2$, pp. 402-411, April 2010.

[20] F. Mekri, J.F. Charpentier, S. Benelghali and X. Kestelyn, "High order sliding mode optimal current control of five phase permanent magnet motor under open circuited phase fault conditions," in Proceedings of the 2010 IEEE VPPC, Lille (France), pp. 1-6, September 2011.

[21] X. Kestelyn and E. Semail, "A vectorial approach for generation of optimal current references for multiphase permanent-magnet synchronous machines in real time," IEEE Trans. Industrial Electronics, vol. 58, n 11 , pp. 5057-5065, November 2011.

[22] F. Locment, E. Semail and X. Kestelyn, "Vectorial approach based control of a seven-phase axial flux machine designed for fault operation," IEEE Trans. Industrial Electronics, vol. 55, n ${ }^{\circ} 10$, pp. 3682-3691, October 2008.

[23] L. Parsa, N. Kim and H.A. Toliyat, "Five-phase permanent-magnet motor drives," IEEE Trans. Industry Applications, vol. 41, n 1 , pp. 30-37, January-February 2005.

[24] B. Beltran, T. Ahmed-Ali and M.E.H. Benbouzid, "Sliding mode power control of variable-speed wind energy conversion systems," IEEE Trans. Energy Conversion, vol. 23, n², pp. 551-558, June 2008.

[25] B. Beltran, T. Ahmed-Ali and M.E.H. Benbouzid, "High-order sliding mode control of variable speed wind turbines," IEEE Trans. Industrial Electronics, vol. 56, n ${ }^{\circ}$, pp. 3314-3321, September 2009.

[26] N.E.A.M Hassanain and J.E. Fletcher, "steady-state performance assessment of three- and five-phase permanent magnet generators connected to a diode bridge rectifier under open-circuit faults," IET Renewable Power Generation, vol.4, n5, pp 420-427, September 2010.

[27] A. Levant and L. Alelishvili, "Integral high-order sliding modes," IEEE Trans. Automatic Control, vol. 52, n 7, pp. 1278-1282, July 2007.

[28] M.T. Mohammad and J.E. , M.T.; Fletcher, "Five-phase permanent magnet machines, advantages and applications," in Proceedings of the 2010 IET PEMD, Brighton (UK), pp. 1-5, April 2010.

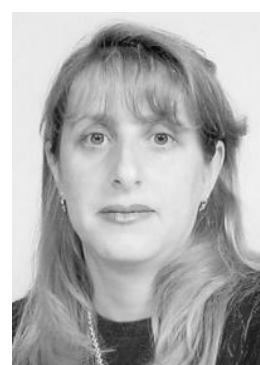

Fatiha Mekri was born in Algiers, Algeria, in 1970 She received the B.Sc., the M.Sc., and the Ph.D. degrees all in electrical engineering from the University of Sciences and Technology of Oran, Oran, Algeria in 1994, 2001, and 2007, respectively. The Ph.D. studies were done in collaboration with the University of Nantes, Saint-Nazaire, France.

After receiving the Ph.D. degree, she joined the French Naval Academy, Brest, France as an Assistant Professor. Since September 2011, she joined the University of Saida, Saida, Algeria as an Associate Professor of electrical engineering. Her main area of interest includes power electronics control, power quality applications, active power filters, electrical drives and renewable energy applications. 


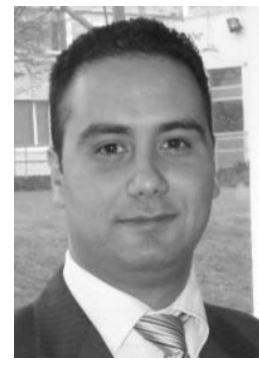

Seifeddine Ben Elghali (S'04-M'10) was born in Téboulba, Tunisia, in 1981. He received the B.Sc degree in electrical engineering in 2005 from ENIT, Tunis, Tunisia, the M.Sc. degree in Automatic Control in 2006 from the University of Poitiers, Poitiers, France, and the Ph.D. degree in Electrical Engineering in 2009 from the University of Brest, Brest, France.

After receiving the Ph.D. degree, he joined the French Naval Academy, Brest, France as an Assistant

Professor. In September 2010, he joined the University of Aix-Marseille 3, Marseille, France, as an Associate Professor of electrical engineering. His current research interests include modeling and control of renewable energy applications.

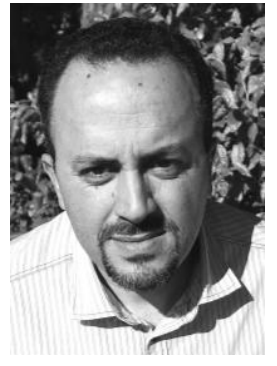

Mohamed El Hachemi Benbouzid (S'92-M'95SM'98) was born in Batna, Algeria, in 1968. He received the B.Sc. degree in electrical engineering from the University of Batna, Batna, Algeria, in 1990, the M.Sc. and Ph.D. degrees in electrical and computer engineering from the National Polytechnic Institute of Grenoble, Grenoble, France, in 1991 and 1994, respectively, and the Habilitation à Diriger des Recherches degree from the University of Picardie "Jules Verne," Amiens, France, in 2000.

After receiving the $\mathrm{Ph} . \mathrm{D}$. degree, he joined the Professional Institute of Amiens, University of Picardie "Jules Verne," where he was an Associate Professor of electrical and computer engineering. In September 2004, he joined the University Institute of Technology (IUT) of Brest, University of Brest, Brest, France, as a Professor of electrical engineering. His main research interests and experience include analysis, design, and control of electric machines, variable-speed drives for traction, propulsion, and renewable energy applications, and fault diagnosis of electric machines.

Prof. Benbouzid is a Senior Member of the IEEE Power Engineering, Industrial Electronics, Industry Applications, Power Electronics, and Vehicular Technology Societies. He is an Associate Editor of the IEEE TRANSACTIONS ON ENERGY CONVERSION, the IEEE TRANSACTIONS ON INDUSTRIAL ELECTRONICS, the IEEE TRANSACTIONS ON SUSTAINABLE ENERGy, and the IEEE TRANSACTIONS ON VehicUlar TECHNOLOGY. He was an Associate Editor of the IEEE/ASME TRANSACTIONS ON MECHATRONICS from 2006 to 2009. 